\title{
O Que pode um professor de filosofia? - A reflexão em torno da responsabilidade ético-política do ensino de filosofia
}

\author{
BRUNO TAVARES ASSUNÇÃO *
}

\begin{abstract}
RESUMO O presente trabalho tem por objetivo refletir e apontar as implicações ético-políticas em torno do ensino de Filosofia. Há quase uma década o ensino de Filosofia teve a sua reinserção no currículo do ensino médio, suscitando uma gama de discussões e medidas em seu entorno. Tendo como viés o conceito de responsabilidade, a partir do existencialismo de Jean-Paul Sartre, é fundamental a reflexão acerca da questão do ensino filosófico considerando a esfera da responsabilidade para com o outro. Compreender a relação apontada por Sartre, esta relação do Para-si e do Para-outro, é fundamental para dimensionar a importância de sua filosofia como constituinte de uma perspectiva do homem não apenas para o início do século, mas, sobretudo, para retornarmos ao passado e nos projetarmos ao futuro com o intuito de objetivarmos a ideia de responsabilidade, acima de tudo. Garantir o acesso ao ensino filosófico compreende, acima de tudo, um compromisso com toda a humanidade. Somente a partir da reflexão de sua existência, da existência do outro e do mundo, o Para-si compreende-se como consciência partícipe de seu papel político no mundo e a experiência da filosofia torna-se possível.
\end{abstract}

PALAVRAS-ChaVe existencialismo; ensino de filosofia; filosofia no Brasil.

o "outro", que neste caso me refiro, ao corpo discente ou aluno, é reconhecido como portador de uma humanidade e deve estar no cerne da atividade de ensinar, ou na pretensão de ensinar algo. É, justamente, no reconhecimento do "outro", como portador de uma consciência, e não apenas de um objeto corpóreo, que o reconheço como dotado de humanidade, e reconheço a mim mesmo como também dotado desta humanidade. É esta humanidade que nos aproxima, que nos coloca numa relação

* Mestrando em Filosofia pela UERJ 
de igualdade e, acima de tudo, de responsabilidade. A condução do olhar ou de uma escuta filosófica, vide a que já realizava Sócrates, na antiguidade clássica, era construída justamente por meio do reconhecimento do nada saber, como uma abertura para o novo. É nesta abertura para o novo, o inesperado ou, até mesmo, o absurdo, o não pensado, que deve ser pautada a atividade de ensinar filosofia.

Os textos filosóficos, ou a análise desses textos, por si só, não se apresentam como suficientes para a construção de uma reflexão por parte deste “outro”, isto é, com quem justamente se estabelece uma relação de responsabilidade entre o professor de filosofia e o aluno. É necessário que haja, por parte do professor, significativa sensibilidade, ou a adoção de um compromisso, para que estabeleça um referencial. Tal referencial, deve ser, prioritariamente, o cotidiano, a vida real do aluno. É a partir do cotidiano que se torna possível a viabilização de tal interação.

Por esta via, será necessário realizar um breve histórico do ensino filosófico no Brasil, sistematizando as suas mais diferentes fases. Convém ainda, apontar os interesses do Estado com o ensino filosófico, nas diferentes fases a serem abordadas, assim como os aspectos da formação de professores de filosofia. A partir desta perspectiva, o ensino de filosofia sempre ocupou um lugar de desmerecimento, não apenas nos currículos, mas, sobretudo, no próprio âmbito social. E, por intenção final, direcionar possíveis caminhos para o impasse do ensino filosófico no Brasil.

A partir da aprovação da Lei no. 11.684 do Conselho Nacional de Educação, que alterou o artigo 36 de Lei de Diretrizes e Bases da Educação (LDB/96), a Filosofia, assim como a Sociologia, tornou-se obrigatória nos três anos do Ensino Médio.

A trajetória do ensino de Filosofia no Brasil está diretamente ligada ao grupo político dominante, e consequentemente, às suas ideologias. De fato, observa-se que o ensino filosófico, numa conceituação kantiana, propriamente falando, passou por diversas idas e vindas. Sobretudo, no período da Ditadura Militar, a Filosofia era considerada subversiva, de caráter perigoso e duvidoso.

Diante da escassez de licenciados em Filosofia, admitiram-se licenciados, ou não, das nomeadas disciplinas correlatas, que apresentassem carga horária mínima de 16oh, de disciplinas de Filosofia em cursos de graduação, pós-graduação ou extensão. 
Observa-se que, mesmo após nove anos da aprovação da Lei e extinto o prazo máximo para a adaptação das instituições, estas não realizam o cumprimento da lei, tornando o ensino de Filosofia facultativo, em, pelo menos um dos três anos do Ensino Médio. Outro fato relevante a ser levantado, é o crescimento gradual dos cursos de graduação e pós-graduação em Filosofia no Brasil, assim como a crescente procura por tais cursos.

No dia 22 de setembro de 2016, foi encaminhado ao Congresso Nacional, o texto base da reforma do Ensino Médio. A mudança, segundo o Ministério da Educação, visa possibilitar ao aluno a de escolha, de acordo com as suas aptidões.

Após anos de insistência pelo retorno da filosofia ao Ensino Médio, a reforma implementada pela Medida Provisória (MP) 746/2016 retira, não apenas a Filosofia, mas as demais disciplinas, principalmente da área das Ciências Humanas, de uma posição que sempre deveriam ter ocupado. De fato, a reforma do ensino médio causa um retrocesso e parece ser o alicerce de uma política voltada para a formação de mão de obra qualificada. Face a esse projeto, o ensino médio técnico tem sido amplamente incentivado pelo governo, demonstrando a política em torno de uma formação para a ocupação do mercado de trabalho.

O currículo do Ensino Médio, segundo a proposta, será composto majoritariamente por disciplinas determinadas pela Base Nacional Comum, ainda em discussão, e segundo as aptidões do aluno, pelo seguinte eixo optativo: linguagens e suas tecnologias; matemática e suas tecnologias; ciências da natureza e suas tecnologias; ciências humanas e sociais e suas tecnologias; formação técnica e profissional. A reforma amplia a carga horária do ensino médio e possibilita que "portadores de um notório saber" lecionem, ainda que não possuam formação ou licença para tal atividade.

Inicialmente, a maneira como a reforma foi proposta, por meio de uma medida provisória, impossibilitando uma ampla discussão com a sociedade, gerou uma série de questionamentos quanto à sua legitimidade. Em uma consulta pública, realizada pelo Senado Federal, acerca da Medida Provisória que determina a reforma do Ensino Médio, foram colhidos 73.564 votos contrários à reforma e 4.551 votos a favor da reforma. O expressivo resultado da consulta revela não apenas a preocupação da população com a medida, mas, sobretudo, a dubiedade diante da inconsistência e obscuridade das propostas. Além de uma realidade educacional não condizente com a reforma, a medida esbarra na questão econômica, visto que os Estados, responsáveis pela edu- 
cação do segmento de Ensino Médio, já demonstram incapacidade de gestão do atual modelo escolar.

Especificamente, o objeto do presente estudo, pretende compreender a situação real do ensino filosófico no Estado do Rio de Janeiro. No último ano, a Filosofia, passou a ocupar dois tempos de aula semanais, em cada uma das séries do Ensino Médio. De fato, um avanço a ser apontado, ainda sob um preocupante panorama. Diante da carência e da não regularização de professores aprovados e convocados nos últimos concursos, a Secretaria de Estado de Educação do Rio de Janeiro, tem alocado professores de outras disciplinas para lecionar Filosofia.

Compreender a relação apontada por Sartre, esta relação do Para-si e do Para-outro, é fundamental para dimensionar a importância de sua filosofia como constituinte de uma perspectiva do homem não apenas para o início do século, mas, sobretudo, para retornarmos ao passado e nos projetarmos ao futuro com o intuito de objetivarmos a ideia de responsabilidade, acima de tudo.

No âmbito da filosofia contemporânea, Jean-Paul Sartre certamente possibilitou novas estruturas de pensamento para se refletir sobre o problema central de sua filosofia: o ser humano, sua liberdade e sua relação para com o mundo. Anteriormente à Sartre, a questão do homem foi secundarizada pela filosofia, que passou a investigar, prioritariamente, questões relacionadas ao conhecimento.

Ao final do século XIX, Soren Kierkegaard, já inicia a retomada da questão do ser humano (o existente, o indivíduo, o sujeito) e constitui os primeiros esboços para a corrente existencialista. O existencialismo de Sartre leva a liberdade a ocupar uma questão ainda mais radical, em meio a uma verdadeira crise do homem, em meio às guerras que abalaram o início do século XX e tantos outros conflitos.

Ao indagar sobre a liberdade, Sartre a compreende como a única essência possível do ser humano. Se, é possível afirmarmos uma natureza comum e universal, esta natureza é a liberdade. Segundo Sartre, a liberdade é uma questão incondicional, não há a possibilidade de escolha de deixar de ser livre. Esta condição de não poder escolher deixar de ser livre, pois este ato é por si só uma escolha, aponta para a questão paradoxal em torno do conceito de liberdade para Sartre. A condenação à liberdade, paradoxo desta relação, nos remete à questão da angústia, já apontada por Kierkegaard, 
como uma perfeita expressão da natureza humana. É essa angústia diante da liberdade, que configura a liberdade como um livre querer. No entanto, a angústia não pode ser compreendida como um molde paralisador da ação, mas sim, para uma angústia que leve à ação, conhecida por todos que possuem a reponsabilidade.

As condições sociais, no caso as situações que Sartre conceitua, não impelem ou não podem constituir uma justificativa para o exercício da liberdade. A liberdade não é dependente de forças exteriores ao Para-si. A liberdade estaria condicionada aos interesses sociais, mas não determinada por estes. Estas seriam apenas um ponto de partida, mas não sua gênese.

Assim, não temos nem atrás de nós, nem diante de nós, no domínio luminoso dos valores, justificações ou desculpas. Estamos sós e sem desculpas. É o que traduzirei dizendo que o homem está condenado a ser livre. Condenado porque não se criou a si próprio; e, no entanto, livre porque, uma vez lançado ao mundo, é responsável por tudo quanto fizer. ${ }^{1}$

A crescente implementação de um ensino técnico, com o exclusivo intuito de formação de mão de obra minimamente qualificada, para assumir prontamente postos de trabalho, vai de encontro ao que Nietzsche já apontava em O futuro dos nossos estabelecimentos de ensino.

Ao analisar a situação das instituições de ensino na Alemanha do século XIX, Nietzsche apontava que a formação dos jovens estaria sendo realizada para atender uma formação “técnica”, e não mais humanista. A cultura e seu resgate de uma cultura germânica, tema tão debatido por Nietzsche, havia sido deixada em segundo plano. O espaço do refletir, do criticar e do questionar, dava lugar ao fazer e ao construir. De fato, assim como o panorama apresentado por Nietzsche na Alemanha do século XIX, no Brasil, desde a segunda metade do século XX, o sistema de ensino tem sido dirigido essencialmente para o ensino técnico, sobretudo nos níveis do Ensino Médio.

Durante a primeira metade da década de 1970, ocorreu no Brasil uma reforma do Ensino Médio, decretando o fim da escola tradicional, com um viés humanista, em prol de uma formação voltada para os setores da economia em questão. A partir de tal reforma, diversas disciplinas ligadas às áreas de ciências humanas, passaram por uma

1 SARTRE, 2011, p. 15. 
espécie de esvaziamento e, consequentemente, a Filosofia foi eliminada progressivamente do novo currículo do secundário. Ainda em um primeiro momento, compunha os currículos como disciplina optativa, mas, posteriormente, foi totalmente banida. Por meio de lutas coletivas, foi reintroduzida nos currículos das secretarias estaduais de educação, ainda sob caráter optativo, no Rio de Janeiro, a partir de 1980.

Neste novo horizonte do ensino de Filosofia, havia uma nova questão a ser refletida: o panorama socioeducacional que, por sua vez, não estaria mais em consonância com a realidade do país antes de sua retirada.

De fato, a inserção e a retirada do ensino filosófico, apresenta uma relevante questão em torno do seu aspecto ético-político.

Nesta perspectiva, a filosofia tem seu sentido retirado, sobretudo em uma atualidade imediatista e pragmática, na qual a razão de ser tem que, obrigatoriamente, estar pautada em sua utilidade. Como aponta Cerletti:

É possível constatar, de maneira cada vez mais premente, que há que começar a justificar com muito cuidado o sentido da presença da filosofia na escola, junto a diversos saberes e atividades de nossa vida de hoje. É sabido que, na hora de lutar por espaço nos planos de estudo, aquele passado sublime da filosofia tem pouco valor quando se trata de decidir algumas horas nas grades curriculares, e aqueles que defendem espaços filosóficos devem disputá-los palmo a palmo com os especialistas de outras disciplinas que, por sua vez, reivindicam a necessidade e a importância prática dos próprios campos. ${ }^{2}$

Diante deste preocupante horizonte acerca da Filosofia e seu ensino, é necessário refletir sobre a responsabilidade ético-política da questão e, acima de tudo, do professor de Filosofia. Mediante tal problemática, o intuito do presente trabalho, será construído a partir da conceituação de responsabilidade na perspectiva de Jean-Paul Sartre. A responsabilidade, como cerne de entendimento da questão da liberdade para Sartre é, acima de tudo, um compromisso que se assume não apenas para si, mas para toda uma humanidade, decerto “sou responsável por mim e por todos, e crio uma certa imagem do homem por mim escolhida; escolhendo-me, escolho o homem.”3 
Ao assumir um compromisso para com a humanidade, o Para-si constrói a dimensão política de sua existência. “O Nós é uma certa experiência particular que se produz, em casos especiais, sobre o fundamento do ser-Para-outro em geral. O ser-Para-outro precede e fundamenta o ser-com-o-outro." 4

Acima de tudo esta relação do ser-com-o-outro precisa estar pautada na questão da responsabilidade. Ao perceber o outro, não mais como um mero objeto, mas especialmente, como um corpo dotado de consciência e de subjetividade, perpassando pela questão da alteridade, é estabelecida a relação de intersubjetividade, perpassando pela questão da alteridade, é estabelecida a relação de intersubjetividade. Como afirma Sartre:

Por conseguinte, neste plano, nós preocupamo-nos com uma moral de ação e de compromisso. No entanto, nos objetam-nos ainda, a partir destes poucos dados, que encerramos o homem na sua subjetividade individual. Também aí nos entendem muito mal. O nosso ponto de partida é, com efeito, a subjetividade do indivíduo, e isso por razões estritamente filosóficas. ${ }^{5}$

Se a liberdade para Sartre é justamente, a transcendência, o ir além do estabelecido, a Filosofia proporciona. Assim, Sartre conceitua a responsabilidade:

Sou responsável por tudo, de fato, exceto por minha responsabilidade mesmo, pois não sou o fundamento de meu ser. Portanto, tudo se passa como se eu estivesse coagido a ser responsável. Sou abandonado no mundo, não no sentido de que permanecesse desamparado e passivo em um universo hostil, tal como a tábua flutua sobre a água, mas, ao contrário, no sentido de que me deparo subitamente sozinho e sem ajuda, comprometido em um mundo pelo qual sou inteiramente responsável, sem poder, por mais que tente, livrar-me um instante sequer destas responsabilidades $[\ldots]{ }^{6}$

A responsabilidade no entendimento de Sartre, não possui um viés jurídico e sim é compreendida como consciência da liberdade, da liberdade como fundamento primordial e, pela qual, o ser existe. A noção de culpa apregoada pela cultura judaico-cristã não é aceita por Sartre, justamente por não abarcar a consciência do ato. Ao tornar-se responsável, o Para-si se concebe como o realizador de suas ações e pela

\footnotetext{
4 SARTRE, 2011, p. 514.

5 SARTRE, 1973, p. 21.

6 SARTRE, 2011, p. 680.
} 
responsabilidade de si. Sob a ótica do humanismo e na defesa do existencialismo, Sartre afirma que:

O existencialista não tem como pejo em declarar que o homem é angústia. Significa isso: o homem ligado por um compromisso e que se dá conta de que não é apenas ele que escolher ser, mas de que é também um legislador pronto a escolher, ao mesmo tempo que a si próprio, a humanidade inteira, não poderia escapar ao sentimento da sua total e profunda responsabilidade. ${ }^{7}$

Sartre reconhece a imersão do indivíduo e seu reflexo de uma sociedade, um período histórico, uma situação. Ora, não estaria justamente aí a questão da responsabilidade ao ensinar? O próprio fundamento da educação, com o intuito de uma emancipação, seria o reflexo, o resultado de uma sociedade, ou ainda uma relação dialética, na qual os indivíduos, ao escolherem para si mesmos escolhem, na verdade, para todos. Acima de tudo, ao se realizar, o Para-si constrói uma constante ruptura radical com a imanência e com seu passado. É a partir de um horizonte de rupturas com as estruturas e as ideologias dominantes, que a responsabilidade do ensino filosófico necessita estar pautada.

Na reunião de conferências Em defesa dos intelectuais (1994), Sartre reflete sobre a questão do intelectual na sociedade capitalista, na qual observa-se o nascimento de um novo tipo de profissional: o especialista do saber prático. Esse tipo de profissional, que surge em meio ao conflito entre a burguesia e os ideais da Igreja, não constrói, nem faz parte da ideologia burguesa. Sua função é apenas manter determinadas funcionalidades de um sistema e sua educação, como aponta Sartre:

[...] é definida por um sistema constituído acima de tudo (primário, secundário, superior) dar: a) a ideologia que julga conveniente (primário e secundário); b) os conhecimentos e práticas que os tornam capazes de exercer suas funções (superior). Portanto, a priori, ela lhes ensina dois papeis: ao mesmo tempo faz deles especialistas da pesquisa e servidores da hegemonia, que dizer, guardiães da tradição. ${ }^{8}$ 
Ora, tal ideal, de uma formação de mão-de-obra, sobretudo de qualificação técnica, que visa atender ao mercado de trabalho, parece constituir o ideal da reforma do ensino médio, retornando aos moldes, já intencionados, desde a ditadura militar.

O intelectual, segundo Sartre, seria produto de uma contradição. A contradição é própria do ser, concerne ao mundo prático. Sendo assim, em tal situação, encontra-se o professor, pois nele está contido o saber prático, a universalidade, e a ideologia, o particularismo. O intelectual necessita partir de sua própria classe, de sua própria vivência. Uma das questões apresentadas nos Parâmetros Curriculares Nacionais (2002), ao que tange o ensino de Filosofia, “enfatiza a competência da Filosofia para promover, sistematicamente, condições indispensáveis para a formação da cidadania plena" 9 , ou seja, para a práxis. Sartre afirma que:

[...] a práxis comporta o momento do saber prático que revela, ultrapassa, conserva e modifica a realidade. [...] A verdade vem ao ser a partir do não-ser, ao presente a partir do porvir prático. [...]. Disso decorre, que o saber prático de início é invenção. Para serem descobertas, utilizadas e verificadas, é preciso que as possibilidades sejam antes inventadas. Nesse sentido, todo homem é projeto: criador, pois inventa o que já é, a partir do que ainda não é. ${ }^{10}$

O exercício da cidadania é, essencialmente uma questão ético-política que, por sua vez, é permeada pela questão da liberdade do Para-si como sujeito responsável pelo seu exercício. A práxis, é própria de cada indivíduo, a experiência original de toda a dialética. Por meio da práxis, o Para-si percebe-se capaz de executar uma ação que altera o estado de mundo atual, supera uma situação já posta, a transcende. Este compreende o projeto, a capacidade do indivíduo de ir além, de compreender uma situação atual, agir e alcançar algo que ainda não está pronto, próprio da existência humana. Em suma, "Não se trata de escolher a época, mas de se escolher nela.”. ${ }^{11}$

Nesta perspectiva, o ensino filosófico pode oferecer justamente um novo campo de visão/ação para a compreensão das contradições e, consequentemente, por meio da construção do espírito crítico, alicerçar as bases para uma ação refletida. No entanto, como já exposto anteriormente, tal construção desse novo campo de visão/ação,

9 BRASIL, 2011, p. 45.

10 SARTRE, 1994, p. 23.

11 SARTRE, 1968, p. 252. 
vai de desencontro aos ideais das classes dominantes. O ensino filosófico tendo por escopo, a experiência crítica, procura fundamentar as condições de inteligibilidade histórica da práxis.

Para que seja possível um ensino filosófico, este deve ter por alicerce não apenas a teoria ou a história da filosofia, se pautando apenas num modelo de transmissão de correntes filosóficas. Tal possibilidade de ensinar filosofia, ou iniciar uma visão filosófica, precisa ser possibilitada pela vivência da própria filosofia, perpassando pela realidade do Para-si, partindo de sua existência, problematizando-a e, então sim, chegar à conceituação esperada. É partir da própria práxis para transcender a situação posta. A partir da experimentação desses momentos de contradição, de desestabilização, podem surgir inúmeras outras "soluções”, ou ainda, indagações. Sartre, por meio da atividade filosófica, de um intelectual engajado e comprometido com as questões de seu tempo, a utilizará como instrumento para a busca da liberdade, ou seja, como uma ferramenta que possibilite a autonomia do sujeito frente à sua própria existência.

Garantir o acesso ao ensino filosófico compreende, acima de tudo, um compromisso com toda a humanidade. Somente a partir da reflexão de sua existência, da existência do outro e do mundo, o Para-si compreende-se como consciência partícipe de seu papel político no mundo e a experiência da filosofia torna-se possível.

A Base Nacional Curricular Comum e a Reforma do ensino Médio, retiram, não só a filosofia, como diversas outras disciplinas do currículo escolar, de um patamar de merecimento após inúmeras reivindicações de associações, professores e alunos. Tais documentos norteadores trazem obscuridade para o futuro do ensino no Brasil e se resumem a discussões teórico-pedagógicas nada producentes.

Recentemente, um grupo de professores, ligados ao Grupo de Trabalho sobre Direitos à Aprendizagem e ao Desenvolvimento (GT Diad) publicou um material oferece alternativas à Base Nacional Curricular Comum. O grupo constituído por cerca de 80 educadores, das mais diversas regiões e instituições do país, reuniu, em um documento disponibilizado online, um conjunto de discussões elaboradas num período de aproximadamente três anos e solicitadas pelo Ministério da Educação. 
Certamente, o futuro do ensino filosófico no Brasil é permeado por sólidas incertezas. Se as incertezas é que constituem a própria atividade filosófica, tais incertezas do ensino filosófico são permeadas pela obscuridade do futuro.

\section{REFERÊNCIAS BIBLIOGRÁFICAS:}

BRASIL, Secretaria de Educação Média e Tecnológica. Parâmetros curriculares nacionais: ensino médio. Brasília: MEC; SEMTEC, 2002.

Diretrizes Curriculares Nacionais para o Ensino Médio. Brasília: MEC, 2011. Disponível em: <http://portal.mec.gov.br/index.php?option=com content\&view=article\&id=12992> acesso em 27/06/2017. . Medida Provisória $n^{\circ}$ 746, de Setembro de 2016.

CERLETTI, Alejandro. O ensino de filosofia como problema filosófico. Trad. Ingrid Müller Xavier. Belo Horizonte: Autêntica Editora, 2009.

NIETZSCHE, Friedrich. Escritos sobre Educação. Trad. Noeli Correia de Melo Sobrinho. 7 ed. Rio de Janeiro: PUC-Rio, 2011.

SARTRE, Jean-Paul. O Ser e o Nada - Ensaio de uma ontologia fenomenológica. Trad. Paulo Perdigão. 20 ed. Petrópolis, RJ: Vozes, 2011.

. Em defesa dos intelectuais. Trad. Sérgio Goes de Paula. Rio de Janeiro: Editora Ática, 1994 .

O Existencialismo é um humanismo. São Paulo: Nova Cultural. (Coleções Os Pensadores), 1973 .

Situações II. Trad. Rui Mário Gonçalves. Lisboa: Publicações Europa-América, 1968. 